Pouco mais de cinco séculos atrás, segundo consta nas histórias oficiais, os grandes navegantes do Velho Mundo chegavam aos trópicos americanos pela primeira vez. Chegavam à procura de outro continente, o asiático, na interminável caçada de novos caminhos para a Índia. Quando aportaram aqui, no entanto, os marinheiros e suas comitivas não se deram conta da imensa descoberta que haviam acabado de fazer. O que supunham é que haviam realmente chegado à Ásia, e que se encontravam no lado oposto do continente asiático (no que diz respeito à localização da Índia). Só posteriormente é que o homem europeu percebeu que havia chegado a um continente novo para ele, a partir de então chamado de América.

Contudo, para além dos registros que a história admite como verdade, o que importa para este artigo - que pretende tratar de literatura, forma de conhecimento dada à relatividade das coisas - é que tais navegantes, talvez por obrigação hierárquica, registravam textualmente o que ocorria no além-mar, para dar satisfações ao velho mundo dos acontecimentos vivenciados na empreitada ultramarina.

À ótica desses homens, indo em direção ao desconhecido, levando nas costas a necessidade de satisfazer as expectativas de uma sociedade imensa, parece mesmo impensável relatar o fracasso. Seria difícil, naquele momento, dizer que não haviam encontrado nada que valesse a pena, que não fosse rentável, seria inimaginável não provocar a recepção ávida por novidades dos destinatários de tais textos.

Daí é que se pode compreender o motivo de esses relatos soarem hoje, muitas das vezes, mais fortemente como obra de ficção do que como obra histórica propriamente dita. E de fato assim é que devem ser entendidos, em inúmeros casos. Uma investigação mais detalhada desse momento da história das descobertas dos territórios americanos demonstraria facilmente o teor fictício de inúmeras narrativas que chegavam ao velho continente e sacudiam a imaginação europeia. Há nelas, por exemplo, alusões a seres estranhos, em formas mesmo de monstros que hoje o mundo sabe não passarem de criações fictícias.

Por tudo isso, não seria nenhum exagero dizer que a ficção literária, esta mesma que, ao menos até onde sabemos, se desenvolve desde a Grécia Antiga e que é nosso objeto de preocupação maior, desembarcou nos nossos trópicos já nas primeiras vindas dos homens europeus a estas terras. Não desembarcou deliberadamente em forma que se pretendesse literária, mas desembarcou.

Desembarcou como necessidade de suprir o real, porque este não deve ter satisfeito, ao menos de início, as expectativas daqueles que aqui primeiro chegaram. Como muito já se defendeu na modernidade, eis aqui um dos grandes papéis a que a ficção se presta, o de criar no mundo imaginário aquilo que a realidade não dá (ISER, 2013). Todo homem, de fato, como pregaram e pregam os teóricos da Estética da Recepção, é um ficcionista em potencial e, em dado momento de sua vida, sentirá necessidade de lançar mão da sua capacidade de criar, por não encontrar nela as condições ideais de autossatisfação.

Talvez aqui, portanto, esteja o germe da estrutura de boa parte da literatura latino-americana, no sentido construtivo-formal mesmo da expressão. Sacando o caminho da história, os escritores ficcionais dele se apropriaram para criar um novo conceito de escrita artística, absolutamente original.

Se histórias que se pretenderam verídicas forjaram discursos ficcionais, a ficção certamente enxergou nisso um terreno fértil para a construção de suas narrativas. É evidente a proximidade entre os relatos suprarreais, não naturais, dos navegantes e o mundo fantástico de um Cem anos de solidão (2014), por exemplo. Aliás, é emblemático dizer que essa obra lida, quanto ao tema, justamente com o embate entre civilizações estranhas entre si, e que Macondo, local onde se passa a estória de García Márquez, é a alegoria da América Latina.

Também é notório o fato de que boa parte de literatura latino-americana se dedica a construir a figura do outro, do alter, e é perfeitamente possível que esse movimento esteja ligado ao dos navegantes que relataram as figuras daqueles que lhes eram desconhecidos, criando assim seres estranhos, os supostos monstros, diferentes de tudo aquilo que já se viu, dando vazão talvez ao sentimento de estranheza ante a novidade de viver de maneira diferente - pensemos neste momento na importância do mito na literatura, como sinalizou Stierle (2006).

O que parece, portanto, é que nos deparamos agora com uma escrita ficcional ligada, no que diz respeito à sua forma, à identidade originária do lugar de que faz parte. Literatura, história, sociologia e antropologia parecem imbricar-se. Como, de maneira muito perspicaz, assinalou González Echevarría, a origem de muitos narradores ficcionais latinos, pode-se dizer sem medo, certamente está ligada ao discurso pretensamente real dos primeiros viajantes (2000).

Narrar o outro significa narrar aquilo que não é de domínio próprio. Significa lançar o olhar sobre aquilo que não se compreende. Significa apreender com nossa perspectiva, com seus vícios inerentes, aquilo que ela nunca apreendeu, o que mexe perturbadoramente com seus esquemas e gera assim um sentimento intenso de estranheza e repulsa, e a literatura de hoje sabe disso. 
Muito rapidamente, atentemos para o fato de que há uma linha da psicanálise que prediz que, quando diante de esquemas que não reconhecemos como partes dos nossos círculos, a tendência de nosso comportamento é refutá-los. Para o eu, assim se prega quando o assunto é o inconsciente, tudo que lhe é estranho deve ser refutado, porque significa algum tipo de ameaça. É válido que aqui atentemos para tal ideia, para que ela nos ajude a pensar sobre a construção da figura do diferente, a figura daquele que não é como nós, posto que o olhar sobre o outro e a imagem que dele apreendemos geram consequências importantes ao desdobramento do texto ficcional.

A chegada da modernidade literária revolucionaria a consciência da escrita ficcional a partir de então. A descoberta da perspectiva no sentido técnico, ou seja, a descoberta que a representação do real, tal como ele é, é impossível a todo artista, dado que entre o real e a sua representação há uma subjetividade, levou à reformulação das técnicas literárias, de modo que entrassem em consonância com as novas descobertas. Técnicas essas, é preciso dizer, que poriam no centro da questão o trabalho com a subjetividade, que agora influi conscientemente na estrutura de tudo aquilo que narra.

No nosso caso em específico, olhando também para o problema da América Latina, essa descoberta estética foi posta a serviço da apreensão do tal monstro, dando ainda mais perspicácia literária à tentativa de apropriação da história. O monstro, na verdade, no relato que descreve o outro, está na perspectiva de quem o vê, e não no ser em si. O monstro é aquilo que se forja no discurso de quem se depara com o diferente, com o que o seu sistema não reconhece como semelhante.

Assim, a narrativa que entra no espaço do outro, para lidar com aquilo que não domina, forjará a imagem daquilo que vê à sua maneira. Se a realidade que nos é comum não pode ser traduzida no discurso tal qual ela é, considerando a subjetividade de quem narra, a tradução discursiva da alteridade não tem condições nem de se aproximar, minimamente que seja, da coisa em si.

A nós, portanto, cabe atentar para esse jogo e perceber a relatividade do discurso poético. É, aliás, exatamente isso que ele quer de nós - a relativização do discurso e a percepção das variantes possíveis, mesmo que subliminarmente. Precisamos fazer tal movimento considerando ainda que, na grande maioria dos casos (para não dizer na totalidade deles), a transmissão de uma imagem, seja ela qual for, vem acompanhada de uma intencionalidade, como se verifica nos relatos históricos a que me referi.

\section{A alteridade no contemporâneo}

Transferindo esse debate para o mundo atual, mais próximo de nós e da literatura que nos interessa aqui, ao contrário do que muitos podem pensar (apoiando-se na velocidade acelerada daquilo que chamam de globalização das coisas), o discurso da alteridade ainda nos rodeia, mas agora de outro modo, em níveis a escalas diferentes, evidentemente adaptado ao tempo de que faz parte, assim como o romance. Ele não está só na história, no passado longínquo - muito pelo contrário.

Se lançarmos um olhar minucioso e crítico à nossa volta, por exemplo, considerando aqui a nossa perspectiva como a perspectiva de sujeitos imersos na complexidade das grandes cidades, será possível notar facilmente a fragmentação dos espaços que as constituem. Perceberíamos sem precisar perscrutar muito o caráter cindido das cidades em que vivemos, cisões essas nascidas das mais variadas questões, sejam elas de bases históricas, sociais, econômicas, culturais, étnicas etc.

É certo que nós, no cotidiano de nossos afazeres, sejam eles quais forem, transitamos entre algumas dessas ilhas, que, no que diz respeito à cidadania, formam, em sua soma, aquilo que somos. Ou seja: enquanto cidadãos, somos a interseção das ilhas, dos espaços sociais de que em um ou outro momento fazemos parte.

Nenhum de nós faz parte de todos esses grupos, dado que seria humanamente impossível e que fazer parte desse ou daquele grupo impede necessariamente que se faça parte de um ou de outro. Para além dos lugares que frequentamos, então, todo lugar é o lugar do outro, é o lugar da alteridade, aquele que não o nosso.

Isso significa que, quando ligamos a TV, por exemplo, e lá nos deparamos com notícias a respeito de coisas para nós desconhecidas no âmbito da vivência, somos nós ali os receptores de uma narrativa da alteridade. Não necessariamente estamos diante das coisas como são. O que nos cabe, nesse momento, é atentar para que veículos nos trazem tais informações (quem são os donos do discurso?) e que possíveis intencionalidades estariam por trás da construção desses discursos.

Muito comuns, por exemplo, são os programas de veículos de comunicação brasileiros dedicados a registrar, a seu modo, a vida nas comunidades periféricas das grandes cidades, seja em forma de entretenimento ficcional ou em forma de reportagens investigativas. Como os setores sociais para quem esses entretenimentos ou reportagens se destinam não entram nos espaços ali objetos de atenção, a mídia e o Estado se encarregam de levar até eles as 
imagens dessas comunidades que mais convenientes forem para si. Assim é que surgem, então, no imaginário dos receptores, figuras que correspondem ao interessem de quem as constrói, e não à realidade em si, às vezes forjando inclusive a figura do monstro contemporâneo.

O cinema, também por exemplo, é um dos veículos de formação da imagem do outro (com relação aos receptores pretendidos) dentro dessa lógica das grandes cidades. Recentemente, para ilustrar o que digo, cerca de dois anos passados, fomos todos brindados pelo filme Alemão (2014), dirigido por José Eduardo Belmonte, que, ao que parece, para além de intenções estéticas, tem como ideia central levar ao seu público os bastidores de uma guerra travada entre o Estado e um complexo de favelas do Rio, do qual boa parte da população não considera se aproximar no âmbito da realidade, para assim formular e defender as suas teses.

A própria literatura, durante muitíssimo tempo (não me cabe aqui assumir um discurso corporativista), contribuiu significativamente para a afirmação de imagens estereotipadas e preconceituosas. Não é difícil imaginar que assim tenha sido, se considerarmos que o grosso do que se fez quanto a textos ficcionais até hoje, ao menos no Brasil, é de autoria de gente que provém das classes mais abastadas, que muitas vezes dedicaram-se a forjar imagens do outro periférico via apenas discurso de terceiros, sem qualquer vivência direta. E assim tem sido desde que começamos a produzir alguma coisa. Apenas mais recentemente, sobretudo do último meio século para cá, é que se pode notar um movimento contrário, no qual vozes que partem das periferias sociais também assumem lugar de destaque nas produções de nossas ficções.

É por esse prisma, o dos sujeitos que lançam olhares sobre aquilo que não lhes pertence, mais especificamente dentro das grandes cidades, que proponho aqui uma leitura, talvez inusitada, do romance Passageiro do fim do dia (2010), de Rubens Figueiredo. Ciente, sem dúvida alguma, do problema da perspectiva dentro dessa discussão, o autor urde um discurso comprometido com o real e com o fictício, que não são necessariamente excludentes, bastando apenas que cada forma discursiva respeite a si mesma no que diz respeito às suas questões estruturais. Alia-se assim a uma linha ficcional latino-americana, amplamente dedicada ao problema da alteridade que norteia muito do que há entre nós desde a chegada dos europeus.

\section{A alteridade em Passageiro do fim do dia}

Como disse logo acima, para reconhecer que há um outro, para reconhecer que há o diferente, é preciso, antes, que se faça uma delimitação da perspectiva de quem olha. Falar da existência da alteridade somente é possível dentro da lógica da relatividade, porque marcar alguma diferença exige que se estabeleça comparações com relação a alguma outra coisa, tida evidentemente como semelhante. Aqui, portanto, se a pretensão é perceber o discurso de alguém sobre aquilo que lhe é inteiramente diferente, é preciso identificar quem é esse alguém. É preciso perceber quem é a perspectiva que analisa o objeto que difere de si.

O romance Passageiro do fim do dia (2010), de Rubens Figueiredo, se constrói pela lógica e pela subjetividade de Pedro, personagem longe de viver uma vida abastada de posses, mas ainda mais longe de pertencer a grupos sociais intensamente desfavorecidos pela sociedade, pelo Estado. Um tipo de classe média, portanto, que não tem, mas que pretende ter ou imagina ter. É por meio dele, com todas as suas inerências, que olhamos as coisas em volta.

Esse personagem, o enredo é bem simples, inicia uma viagem de ônibus que vai de uma região central de sua cidade até a periferia dela, onde reside sua namorada, Rosane. Todo o romance acontece no tempo desse percurso, cerca de duas horas. Enquanto Pedro viaja, recebemos o relato de sua interioridade (com toda interação entre o que ocorre no momento do trajeto e as digressões mnemônicas de Pedro), dedicada, sobretudo, ao impacto que recebe daquilo que percebe não ser do seu mundo. Eis o romance inteiro, de ponta a ponta. Como é próprio dos tempos mais próximos ao nosso, o enredo de um texto fictício não tem grande importância (BAKHTIN, 1993) - é quase sempre um pretexto para questões outras.

Alguns aqui podem questionar o apontamento que venho fazendo quanto à perspectiva de Pedro, considerando que todo o texto é narrado na terceira pessoa gramatical, e, portanto, não é a voz de Pedro que nos fala. Sim, é verdade, não é Pedro quem nos fala diretamente. Mas é preciso que consideremos aqui o caráter personativo (SOUZA, 2010) desse narrador. Ele não é Pedro, mas despersonaliza-se em absoluto para narrar a perspectiva de Pedro, desenvolvendo na sua linguagem a perspectiva, o filtro do personagem-centro.

Lembremos, por exemplo, para esclarecer esse movimento técnico, do que Graciliano Ramos faz em Vidas secas (2013). Não são os personagens que falam, mas são as suas impressões que chegam até nós, via o narrador despersonalizado. Trata-se, portanto, do que Autran Dourado chamou em seu estudo sobre o romance moderno, intitulado Uma poética de romance: matéria de carpintaria (1976), de falsa terceira pessoa do discurso ficcional. 
Já de saída, na abertura do romance, embora ainda numa localização da cidade do qual ainda se sente parte, Pedro já articula o discurso da alteridade, que marca sua diferença ante as pessoas ali à sua volta, porque, no ponto de ônibus em que está, Pedro percebe que as pessoas junto dele pertencem a um mundo que não o seu. Pedro "não podia ver as pessoas na fila como seres propriamente iguais a ele" (FIGUEIREDO, 2010, p. 9). As mínimas semelhanças entre eles "não bastavam para fabricar um sangue comum" (FIGUEIREDO, 2010, p. 9).

Trata-se do momento em que Pedro vai pegar o ônibus (que se assemelha às naus dos navegantes antigos, indo ao diferente) para a casa de Rosane, sua namorada, no cair duma tarde de sexta-feira, após o expediente, para lá passar o final de semana, o que vinha fazendo já há algum tempo. Como aquela era a hora em que as pessoas de expediente comum voltavam para suas casas, lá estavam pessoas que também moravam no bairro de Rosane, chamado Tirol, saídas do trabalho pelo centro da cidade e retornando aos seus lares distantes, como é próprio das nossas grandes cidades. Assim, como se vê nas sentenças destacadas acima, Pedro já agora enfrenta o choque com a diferença, e tem consciência disso.

É importante sublinhar que Pedro, muito emblematicamente, traz consigo um livro sobre as andanças de Charles Darwin pelo mundo, inclusive "pelos países do sul" (FIGUEIREDO, 2010, p. 21), o que deixa esse movimento mais emblemático ainda, se considerarmos aqui a relação da obra de Darwin com as experiências de Pedro - um livro, aliás, pelo qual nosso protagonista tem grande estima.

Como sabemos (essa informação é crucial para a interpretação do romance em jogo), Darwin se notabilizou por elaborar uma teoria científica que dá conta da evolução dos seres na terra, e fez isso através da observação minuciosa e da confrontação de seres diferentes entre si, ou seja, explorando o diferente, o outro.

Não é à toa, portanto, que Pedro traz consigo uma obra como essa e não é também à toa que a todo momento o relato vivenciado por Pedro seja interrompido para que se insira no texto passagens encontradas nas vivências de Darwin. Pedro, assim entendo, é uma espécie de Darwin da estória de Rubens, é aquele que está ali para observar o outro e perceber as relações de sobreposição entre grupos. É por isso que suas observações são tão detalhadas. Ele "enxergava bem" (FIGUEIREDO, 2010, p. 11), "tentava imaginar como eram os moradores e em que trabalhavam" (2010, p. 41), "sentia-se em certos momentos o observador de uma civilização alheia" (2010, p. 75).

Atentemos, como forma de reforçar a relação direta entre Darwin e Pedro, para os trechos do romance em que Rubens Figueiredo insere, entre passagens dadas à subjetividade de Pedro avaliando as relações sociais dentro da cidade, considerações de Darwin quanto a animais na luta pela vida, no jogo de caça e presa, como, por exemplo, quando se fala da "vespa e a aranha - o tirano e a vítima - Pepsis e Lycosa" (FIGUEIREDO, 2010, p. 41). Inseridos nesses ambientes discursivos, de atenção às relações humanas dentro do espaço urbano, esses trechos me parecem uma metáfora da luta de classes, que Pedro, nosso Darwin, vem presenciando, e é no mínimo curioso que Rubens estabeleça uma relação homem-animal para tecer tais reflexões sociológicas.

Dentro do ônibus, em muitos momentos, Pedro consegue perceber com ainda mais nitidez o caráter da cidade cindida, porque, enquanto viaja, nosso personagem, durante boa parte do percurso, usa fones de ouvidos, conectados numa estação de rádio da cidade. Na programação, um discurso totalmente desconectado com a realidade do ônibus. Ouvia-se uma voz de mulher que anunciou "a cotação do dólar, do euro, do ouro e do barril de petróleo. Mencionou a taxa de juros do Banco Central e os índices da bolsa de valores de Nova York, Tóquio e de São Paulo, em minúcias que chegavam aos centésimos" (FIGUEIREDO, 2010, p. 16).

Se nós considerarmos que, naquele momento, o bairro Tirol, como o enredo nos faria saber mais adiante, passava por alguma turbulência, por algum momento de violência generalizada, o discurso radiofônico, que aqui me parece a alegoria dos grupos midiáticos que nos cercam (e evidentemente as pessoas para quem ele se dirigem), o descaso fica ainda mais potencializado. É preciso destacar que os passageiros tinham ciência disso. Queriam saber do que se passava no lugar para onde se destinavam, mas sabiam que nas mídias disponíveis a eles "não iam mesmo falar nada do assunto" (FIGUEIREDO, 2010, p. 35), a não ser que ele respingasse para além dos limites geográficos do próprio bairro.

Dezenas de páginas adiante, em movimento de ironia, o texto nos dá onde naquele momento está a preocupação pessoal da radialista, que, por sua postura, pelo tom de voz, pela leveza com que fala, não parece mesmo interessada em dar atenção a qualquer coisa esteja para além da sua própria bolha:

Então era isso, Pedro quase riu ao saber: no dia seguinte, a tal mulher iria para a praia. Devia estar contente por ter acertado suas previsões, por ter confiado nos ganhos e, em prêmio por sua lealdade, agora iria para a praia. Não uma dessas praias por aqui, mais próximas de casa, é claro, uma praia aonde se chega de metrô - uma praia afastada, um hotel de chalés bem separados uns dos outros. Iria com aquele seu namorado de cabelo grisalho, 
força, na mesma luz que se refletia, em cheio, na areia da praia - sob um sol de soja, à beira de um mar de aço. (FIGUEIREDO, 2010, p. 146)

Rubens Figueiredo aqui se assemelha a Drummond, a ponte é bem visível, quando o poeta mineiro, num dos seus inumeráveis lapsos de genialidade, também utilizando-se da imagem da praia, questiona poeticamente o caráter convenientemente alienado dos grupos mais favorecidos de nossa sociedade: "os inocentes, definitivamente inocentes, tudo ignoram/ mas a areia da praia é quente, e há um óleo suave/ que eles passam nas costas, e esquecem" (ANDRADE, 2013, p. 43).

Pedro tem essas visões acentuadas porque, além de observador, como Darwin, está em contato direto com o diferente. Ele é de um mundo e ali está sendo inserido em outro, "como se Pedro fosse alguém que vinha de longe, de um outro país" (FIGUEIREDO, 2010, p. 99), o que faz ressaltar as inúmeras diferenças. É, portanto, de importância cabal que não percamos de vista o problema da perspectiva, que deve a todo momento ser por nós monitorada. Sem ela, ou com a sua variação, o discurso arquitetado por Rubens Figueiredo não teria meios de ser o mesmo, posto que variar a perspectiva significa variar o discurso, o foco, as prioridades, como tornou-se evidente a partir da crise da representação, que trouxe à tona a ideia de que todo discurso, seja ele qual for, está necessariamente condicionado por um ponto de vista.

Se Pedro se sentisse semelhante às pessoas no ônibus à sua volta, se não enxergasse diferenças, não sofreria o choque da alteridade e por consequência nós não o receberíamos. Como a discrepância entre os dois mundos é tamanha, por outro lado, o que fica na verdade impossível de se fazer é não perceber o teor fragmentado do mundo ali exposto.

Mas sublinhemos que essa impossibilidade vem justamente (e só pode ser mesmo assim) do contato direto entre os dois universos absolutamente distintos. "Por mais que Pedro não quisesse acreditar naquilo, e por mais que de fato não acreditasse, acabava se vendo obrigado a integrar-se, a assimilar a separação que parecia vigorar em toda parte. Acabava forçado, também ele, a tomar parte daquilo" (FIGUEIREDO, 2010, p. 148).

As ilhas sociais assim tornavam-se evidentes aos olhos de nosso personagem. Era minuto a minuto cada vez mais impossível não notar, através do choque com o outro, que, fora do seu espaço, aquelas pessoas à sua volta não tinham os mesmos direitos que ele tinha, que sobre elas se lançava um olhar de estranheza, e por isso lá elas se enclausuravam, só saindo em caso de necessidade. Elas sabiam que fora do ambiente em que viviam estavam no "mundo que as deixara para trás, que as empurraram para o fundo: era o mundo de seus inimigos" (FIGUEIREDO, 2010, p. 56).

O mundo deles parecia diferente, retraído, e reduzia-se com tenacidade ao espaço físico do Tirol e, no máximo, dos seus arredores. Fora dali sentiam-se reconhecidos, ameaçados, temidos - fora dali só viam rancor e não havia roupas, linguajar nem maneiras com que pudessem se disfarçar. Quase que só saiam quando precisavam ir a algum hospital ou providenciar algum documento. (FIGUEIREDO, 2010, p. 56)

Pedro "não pôde deixar de observar em muitos moradores a tendência, ou quem sabe a regra, de não cruzar certos limites, de considerar-se estranhos a certos lugares e também estranhos e até hostis às pessoas que residiam nesses lugares" (FIGUEIREDO, 2010, p. 89). "Aquela gente (para a dita alta sociedade) vinha para prejudicar, vinha para desvalorizar a vizinhança de algum jeito, para degradar" (2010, p. 38). "Qualquer coisa desconhecida tinha o efeito de aumentar a ameaça, de produzir a imagem de um risco ainda maior" (2010, p. 52), e fora do Tirol eles se tornavam a ameaça.

Essa imagem de ameaça, que aqui reconheço como uma incorporação da imagem do monstro tão tradicional na literatura latino-americana, vem, como disse no item anterior, da construção de um discurso, por parte da burguesia e do Estado, sobre as comunidades periféricas das grandes cidades. É apenas uma questão de olhar, e por isso é tão cara à literatura.

No romance de Rubens Figueiredo, para se ouvir falar do Tirol fora de seus próprios limites, só através de veículos preocupados em forjar uma imagem pejorativa sobre ele, "nos jornais, na televisão, nos noticiários de crime" (2010, p. 54), quando os ocorridos no Tirol ameaçavam transbordar os seus limites e com isso ameaçavam também o cotidiano pacífico do suposto homem de bem. Fora isso, o desejo da sociedade abastada era que o bairro continuasse separado dela, "bloqueado pelas linhas do trem, cercada por muros altos, [...] isolado por uma vasta área de mata de brejo com mais de cinquenta quilômetros quadrados chamada Pantanal" (2010, p. 38).

\section{A alteridade na América Latina}

Como a intenção deste artigo é evidenciar a semelhança ou a vinculação do romance Passageiro do fim do dia (2010) com uma via de produção literária da América Latina dedicada ao trato com o problema da alteridade, como vimos 
nascida entre nós já com a chegada dos europeus a estas terras - nos seus relatos sobre elas -, trarei agora para esta discussão pequenos exemplos de textos (contos) de autores latinos, que também se dedicam ao choque com o outro, evidenciando brevemente o fio produtivo que liga a todos "nós, latino-americanos" (2011), como disse Ferreira Gullar.

Em "As portas do céu" (2013), conto de Julio Cortázar, nos deparamos com a perspectiva de um advogado aristocrata de Buenos Aires, que sente alguma atração curiosa por aqueles que são diferentes dele, talvez pelo teor exótico que a figura do outro traga à sua vista. A figura desse outro, que nesse conto o advogado Marcelo reconhece expressamente como monstro, o monstro de que tenho falado permanentemente neste trabalho, reside aqui no homem nativo, ou ao menos de origens nativas, do território argentino, também alojado nas periferias das cidades grandes.

Marcelo chega inclusive, em sinal extremado da pretensão de superioridade da racionalidade branca, a escrever fichas sobre o comportamento e as características físicas da gente que é seu objeto de curiosidade, e se relacionava com ela apenas pelo suposto interesse de estudá-la, como a animais. Como não vejo necessidade de me estender aqui quanto ao enredo, basta dizer que o advogado visitava lugares, como um cabaré importante na estória, em que ia apenas para encontrar tais pessoas, e fazia questão de frisar que estava lá apenas "por causa dos monstros, e que não (sabia) de outro onde se possa encontrar tantos juntos" (CORTÁZAR, 2013, p. 16).

É interessante perceber como no conto de Cortázar o choque da alteridade acontece entre a raça que se pretende branca e a raça americana, indígena, comprovando o que tenho dito quanto a apropriação literária do discurso histórico da descoberta europeia deste continente. Choque que também fica evidenciado no texto de Rubens a partir da evocação da figura de Charles Darwin.

Em "There are more things" (1975), Jorge Luis Borges, com sua escrita tradicionalmente enigmática, urde a estória de um sujeito latino-americano rico, estudante de uma universidade norte-americana, mais especificamente de Austin, que precisa voltar à América Latina, por conta da morte de seu tio, provavelmente o dono da fortuna em que o protagonista se apoia.

Na volta, esse protagonista burguês, que é aqui o nosso ponto de vista, toma ciência de que seu tio havia vendido sua casa de veraneio, o que, além de incomodá-lo, deixa-o curioso em saber da identidade do comprador, posto que as mudanças que passaram a ser feitas na casa (de que havia ficado sabendo) após a sua venda soaram a ele um tanto quanto exóticas. "Como seria o habitante?" (BORGES, 1975, p. 40).

Inicia-se aí uma investigação que vai culminar, no fim do conto, na confrontação com "o monstro dos monstros" (BORGES, 1975, p. 42). Antes, no entanto, desse confronto, tomando consciência das mudanças que haviam sido feitas na casa, o protagonista chega a dizer que nada das coisas com que ele se deparava ali "correspondia à figura humana" (1975, p. 45).

É preciso notar que, para ele, o humano corresponde ao pensamento nortista ocidental-trata-se de um personagem altamente instruído na cultura europeia, apesar de latino-americano, e portanto estamos outra vez ante o problema da perspectiva. Tudo que ele vê então lhe causa "repulsa e terror" (BORGES, 1975, p. 45). Não consegue compreender a funcionalidade dos móveis, diferentes de todos que conhecia.

Borges, como é enigmático ao extremo, não chega a desenvolver a figura do monstro - o conto termina antes que isso aconteça. Mas parece evidente que a questão aqui é o contato com o outro, o outro que causa repulsa, embora não se saiba exatamente que outro é esse.

Como vimos, a ideia de monstro, neste caso o comprador da casa, também é aqui desenvolvida, e encontramos mais uma vez evidências do choque cultural norte-sul. Só o que se pode saber é que o outro aqui não pode ser um nortenho, posto que se fosse seria um semelhante, e o choque não ocorreria.

Em "Cabecita negra" (1997), Germán Rozenmacher nos traz um episódio da vida do Senhor Lanari, homem de posses, embora não excessivas, mas o suficiente para que pudesse se reconhecer enquanto alguém superior ao que ele mesmo chama de plebe. O conto é a narrativa de uma de suas noites de insônia que tem a rotina alterada pelo uivo de uma mulher na rua, que gritava "como una perra salvaje" (ROZENMACHER, 1997, p. 22), com uma linguagem "anterior a las palabras" (1997, p. 22), feito fosse ela um animal mesmo.

Lanari, curioso, vai ao encontro da moça, e, ao encontrá-la, logo se dá conta de não é ela "nada más que una cabecita negra" (ROZENMACHER, 1997, p. 24), expressão forjada para designar, do alto e pejorativamente, pessoas com descendência indígena (de cabelos pretos e lisos), que formam boa parte das populações de países da América do Sul. Nosso protagonista faz lá uma caridade, entrega um dinheiro a ela, e passa um tempo "mirándola, con las manos en los bolsillos, despreciándola despacio" (1997, 25). 
O que Lanari não esperava era que nesse momento aparecesse um policial, evidentemente também de origem pobre, também um "cabecita negra", que toma o partido da moça e acusa Lanari como o responsável pela condição inferior dela. O que cabe ainda dizer quanto ao enredo é que o policial, então, dá uma surra em Lanari, num movimento simbólico de insurgência contra a condição de submissão da gente que ele tem por semelhante, e Lanari não entende, imerso na sua alienação, também nos lembrando Drummond, o motivo daquela violência, perguntando-se a si mesmo "qué cuentas le pedían" (ROZENMACHER, 1997, p. 31).

A isso o conto se resume, mais uma vez numa demonstração de choque entre grupos. Mais uma vez, choques entre grupos que procuram se sobrepor uns aos outros, lembrando Rubens e Darwin, e que provém do antigo confronto entre as civilizações branca e nativa, que se desdobrou no confronto das classes sociais das cidades de hoje.

Em "El otro lado" (2004), utilizando-se do realismo maravilhoso tão característico dos hispano-americanos, Laura Santullo parece propor uma leitura diferente quanto ao problema da alteridade, de modo a desconstruir as diferenças que colocam seres humanos uns contra os outros, creio que como forma de conciliação. Em poucas páginas, tece um jogo de espelhos que funde aparentemente imagens as mais distantes entre si. O rosto do personagem-centro se transforma mil vezes, sensível a todas as imagens, aludindo ao fato de que no fundo somos uma coisa só.

De todo modo, mesmo que se olhe a questão dessa ou daquela maneira, o problema da alteridade, como temos visto com o exemplo de todos esses nomes - que são só ilustrativos, posto que há um sem números de autores latinos dedicados a ele -, é um dos nortes da ficção latino-americana. Rubens Figueiredo, a nosso ver, encontra-se dentro desse quadro. Uma leitura atenta do romance Passageiro do fim do dia (2010) pode detectar facilmente a urdidura do discurso do outro, assim como procurei fazer mais acima, aliando-o assim à tradição latina da alteridade. Creio que esse apontamento pode então abrir uma via de leitura de romances nossos ambientados no espaço da cidade, nos colocando, para além de Rubens, ao lado de muita coisa que se faz no resto da América Latina. Mais uma vez invocando o poema de Gullar (2011), vale lembrar que entre nós, latino-americanos, há muito mais proximidades do que distâncias.

Tudo isso não significa, como sugeri anteriormente, que estamos aqui mais preocupados com problemas externos ao texto do que com problemas internos a ele. Esse fenômeno é literário justamente porque somente o discurso fictício pode articulá-lo de tal maneira. A literatura é o lugar da narrativa que absorve o impacto das subjetividades. É o lugar que considera a perspectiva sabendo que contar algo significa contar o que um ponto de vista vê, e não a coisa em si, e a construção da imagem do monstro depende cabalmente disso.

Quando se fala nessas questões, aludindo ao fato de que importa que se dê atenção minuciosa à estrutura do texto, isso não significa que a história tem de ser renegada. O que se diz, na verdade, é que o olhar lançado sobre a história, caso o autor opte por isso, seja literário, e não histórico.

Já que vêm da Grécia muitas das coisas nas quais nos apoiamos até hoje, basta que tomemos como exemplo - altamente emblemático, aliás - a milenar llíada (2001), de Homero, que muitos consideram ser um relato histórico sobre a guerra de Troia, quando, na verdade, é uma obra dedicada à ira de Aquiles quanto a determinadas questões da guerra, ou seja, é uma obra dedicada à perspectiva de alguém sobre alguma coisa, o que influi diretamente na construção estética do seu discurso, assim como no caso de Rubens Figueiredo em Passageiro do fim do dia (2010).

\section{Referências}

ALEMÃO (filme). Direção: José Eduardo Belmonte. RT Features: Brasil, 2014.

ANDRADE, Carlos Drummond de. Sentimento do mundo. São Paulo: Companhia de Bolso, 2013.

BAKHTIN, Mikhail. Questões de literatura e de estética. A teoria do romance. Tradução de A. F. Bernardi et alii. São Paulo: Hucitec; Unesp, 1993.

BORGES, Jorge Luis. There are more things. In: O livro de areia. Tradução de Lígia Morrone Averbuck. Rio de Janeiro: Globo, 1975.

CORTÁZAR. Julio. As portas do céu. In: Bestiário. Rio de Janeiro: Civilização Brasileira, 2013.

DOURADO, Autran. Uma poética de romance: matéria de carpintaria. Edição aumentada e revista pelo autor. São Paulo: Difel, 1976. 
FIGUEIREDO, Rubens. Passageiro do fim do dia. São Paulo: Companhia das Letras, 2010.

GULLAR, Ferreira. Nós, latino-americanos. In: Toda poesia. Rio de Janeiro: José Olympio, 2011.

HOMERO. Ilíada. Rio de Janeiro: Ediouro, 2001.

ISER, Wolfgang. O fictício e o imaginário. Tradução de Johannes Kretschmer. Rio de Janeiro: EdUERJ, 2013.

MÁRQUEZ, Gabriel García. Cem anos de solidão. Rio de Janeiro: Record, 2014.

RAMOS, Graciliano. Vidas secas. Rio de Janeiro: Record, 2013.

ROZENMACHER, Germán. Cabecita negra. In: Cabecita negra (cuentos). Buenos Aires: De la flor, 1997.

SANTULLO, Laura. El outro lado. In: Cuentos. Montevidéu: Banda Oriental, 2004.

SOUZA, Ronaldes de Melo e. Ensaios de poética e hermenêutica. Rio de Janeiro: Oficina Raquel, 2010.

STIERLE, Karlheinz. A ficção. Tradução de Luiz Costa Lima. Rio de Janeiro: UERJ, 2006.

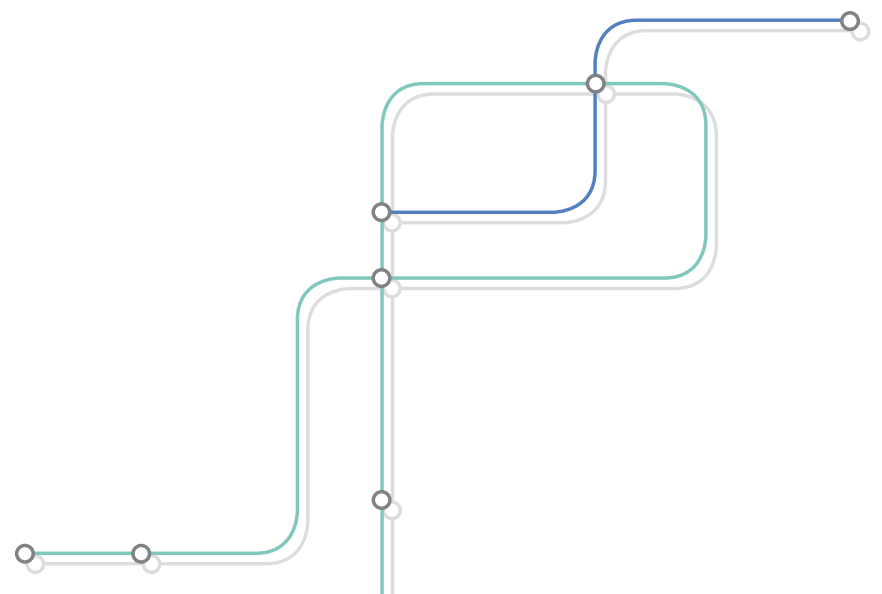

